\title{
Comportamento organizacional e a armadilha da organização reificada
}

\author{
Newton Claizoni Moreno de Melo ${ }^{1}$, Débora Coutinho Paschoal Dourado ${ }^{2}$ \\ e José Ricardo Costa de Mendonça ${ }^{3}$ \\ Universidade Federal de Pernambuco (Recife, Pernambuco, Brasil)
}

\begin{abstract}
Neste ensaio argumentamos contra a tendência reificante de considerar a organização como uma coisa em si, nublando definitivamente as pessoas reais e as relações sociais que nela se estabelecem. Ao mesmo tempo, dada a necessidade do organizar e o crescente papel de mediação exercido pelas organizações na sociedade, reconhecemos que a compreensão dos fenômenos organizacionais é parte importante do esforço para compreender a própria sociedade. Nesse contexto de conhecimento e interesse, defendemos que a disciplina de Comportamento Organizacional está bem posicionada para essa tarefa e possui recursos para contrariar a tendência à reificação da organização. Mas isso não significa que essa disciplina esteja livre de armadilhas. Por isso, questionamos a centralidade da organização nesses mesmos estudos tanto em termos valorativos quanto em termos conceituais. No aspecto valorativo, discutimos a posição de vantagem que a organização goza frente aos indivíduos, particularmente frente aos trabalhadores. No aspecto conceitual, problematizamos a questão do ser da organização, ou pelo menos a ideia que dela se faz. Propomos, ao fim, a recuperação do trabalho como categoria central de análise dos fenômenos organizacionais como forma de superar a ameaça de uma teorização reificante.
\end{abstract}

Palavras-chave: Comportamento organizacional, Processos organizativos, Organização, Reificação.

Organizational behavior and the reified organization pitfall

In this essay, we argue against the reifying tendency of considering the organization as a thing-in-itself, shadowing the real people and the social relations that lays on it. At the same time, given the necessity of organizing and the increasing mediation role accomplished by organizations in society, we recognize that understanding the organizational phenomena is an important part of the effort to understand society itself. In this knowledge and interest context, we claim that the Organizational Behavior discipline is well positioned to this task and has the resources to counter the tendency to reify the organization. But this does not mean that the discipline is not prone to encounter some pitfalls. For this reason, we question the centrality of the organization in these same studies both in terms of value and concept. In the evaluative aspect, we discuss the privileged position that the organization enjoys vis-à-vis individuals, particularly workers. In the conceptual aspect, we problematize the question of the being of organization, or at least the idea of it. Finally, we propose the use of work as the central analytical category of organizational phenomena to overcome the threat of a reifying theoretical conception.

Keywords: Organizational behavior, Organizational processes, Organization, Reification.

\section{Introdução}

$\mathrm{D}$ esde 1922, com a publicação póstuma de Economia e sociedade (Weber, 1922/1978), parece estar claro o papel central, na sociedade contemporânea, daquilo que se convencionou chamar de organizações. De fato, desde a modernidade e, de maneira acelerada a partir do século XX, as organizações absorveram os papeis de diversas outras instituições sociais (Perrow, 1991). Dessa maneira, compreender as organizações seria agora uma chave importante para a compreensão da própria sociedade (Davis \& Marquis, 2005).

1 Doutorando no Programa de Pós-Graduação em Administração (Propad), da Universidade Federal de Pernambuco (UFPE).

Professora do Departamento de Ciências Administrativas (DCA), da Universidade Federal de Pernambuco (UFPE).

3 Professor do Departamento de Ciências Administrativas (DCA), da Universidade Federal de Pernambuco (UFPE). 
Mas, do que estamos falando quando nos referimos à organização? A definição positiva encontrada nos livros-texto ${ }^{4}$ de administração normalmente a conceitua como um conjunto de pessoas (às vezes, um conjunto de recursos) que possuem um ou mais objetivos em comum. Não obstante, as narrativas sobre as organizações frequentemente colocam-nas em oposição às pessoas, contrariando qualquer esperança de um objetivo comum. Dessa contradição destaca-se a maneira como a organização é retratada: como uma entidade ou, para usar um termo mais filosófico, como uma coisa em si. Tomemos um exemplo. No livro The concept of the corporation, Peter Drucker (1993, p. 21, tradução nossa) afirma:

Pode até dizer-se sem muito exagero que a corporação é realmente social e politicamente a priori . . . a sociedade deve insistir na preservação da "preocupação contínua" [a corporação] e deve, se necessário, sacrificar os direitos individuais dos acionistas, credores, trabalhadores e, em última análise, até mesmo dos consumidores.

É somente depois dessa apologia desalmada às organizações (aqui na forma de corporações) que Druker afirma que a corporação é também uma instituição social, uma forma de organização humana.

Essa tensão entre a organização tomada como uma coisa em si e as pessoas reais se reproduz aparentemente nas diferenças fundamentais entre duas importantes disciplinas que orbitam aquilo que se pretende ciência da administração. A primeira disciplina, conhecida como Estudos Organizacionais, tem como horizonte de análise a própria organização. A segunda, o Comportamento Organizacional, focaliza os indivíduos, a relação entre estes e a organização, e o comportamento daqueles nesta.

Neste ensaio, problematizamos a organização vista como "'algo' dentro do qual o processo

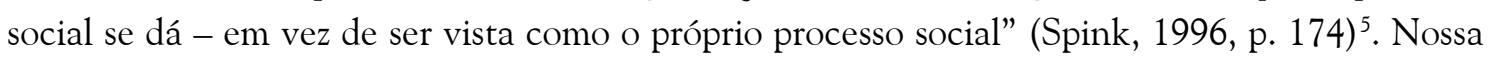
posição é de que o conceito de organização foi reificado ao longo do século XX e de que a aplicação e difusão desse conceito reificado foi legitimada no plano teórico - a partir de interesses bastante práticos -, em larga medida, pelo campo de estudos em administração ${ }^{6}$.

Tal crítica, evidentemente, não é nova. O que nos parece importante é reconhecer que os processos organizativos podem ser elementos inescapáveis para compreender e agir em sociedade, elementos constitutivos do próprio processo social. E porque os processos organizativos não são determinísticos, mas engendrados pela vontade, ação e atribuição de sentidos (Weick, 1979, p. 44), é que elaboramos este ensaio; como uma tentativa de vislumbrar uma base teórica que permita compreender os processos organizativos sem cair na armadilha da organização reificada.

Aqui, argumentamos que a disciplina de Comportamento Organizacional pode ser um alicerce dessa construção teórica. Ao mesmo tempo, problematizamos alguns de seus aspectos que nos parecem críticos. Partimos de uma leitura histórica, examinando três clássicos do início do século XX, a partir dos quais, as narrativas da Teoria Geral da Administração (TGA) são normalmente contadas, Princípios de administração científica de Frederick Taylor (1911/1990), Administração industrial e geral de Henri Fayol (1916/1989) e Burocracia (capítulo de Economia e sociedade) de Max Weber (1922/1978). A partir desses textos, percebemos o que parece ser uma dupla origem do que veio a ser a administração. Do lado norte-americano do Atlântico, Taylor praticava uma administração que se ocupava do trabalho, analisado por ele especificamente no nível da tarefa.

4 O caráter paradigmático e anacrônico dos livros-texto fica evidente no fato de que, nesses relatos, toda a história das mais diferentes abordagens científicas é retratada apenas como passos anteriores necessários e que decorrem naturalmente para a constituição das explicações vigentes no paradigma dominante (Kuhn, 2017).

5 Sobre essa questão, Cf. também Paço-Cunha (2010).

6 Não queremos, com isso, vetar o uso da expressão organização. Queremos afirmar que esta deve ser entendida apenas como um atalho verbal, um nome que aponta para os processos sociais organizativos que ocorrem sob essa denominação. 
Do lado europeu, Weber e Fayol tratavam das propriedades da "organização" e das partes que a constituíam. Em comum, apenas o lugar de destaque que todos eles reservaram para o administrador e o apagamento de muitos conflitos interiorizados na própria noção reificada de organização que começava a se fortalecer.

Duas observações preliminares. Primeiro, este é um ensaio com múltiplas aberturas temáticas. Tentamos nos manter ao centro de uma larga estrada, sem deixar de apontar muitas das saídas que enxergamos como possibilidades para a ampliação das discussões. Segundo, um leitor familiarizado com a teoria social de Marx perceberá que tomamos emprestada sua categoria de reificação e a utilizamos como baliza para nossos argumentos. Este empréstimo, porém, é o limite da aproximação deste texto a Marx. Nosso objetivo não foi o de apresentar uma crítica marxiana à administração ou aos estudos organizacionais ${ }^{7}$. Tampouco nos alongamos excessivamente em discussões amplas sobre a ontologia das organizações em geral ${ }^{8}$. Optamos por nos concentrarmos na armadilha que uma concepção reificada de organização representa para as pesquisas, quaisquer que sejam as posições teórico-epistemológicas esposadas.

\section{Taylorismo, a administração como ciência do trabalho e do trabalhador}

Nas narrativas da TGA, é sempre o taylorismo que aparece imediatamente como o marco inicial da administração "científica", mas qual foi o objeto de estudo de Taylor? Em Princípios de administração científica, Taylor (1911/1990) trata pelo menos de três grandes temas. Primeiro, do estudo sistemático dos tempos e movimentos como forma de determinar a máxima produção e a "única melhor maneira" de realizar uma tarefa. Segundo, da determinação, a partir dessa maneira de realizar a tarefa, de critérios objetivos (e, talvez, discriminatórios) de seleção para os trabalhadores. Terceiro, da formação de um estamento técnico que, apropriando-se do saber operário, passa a controlar a força de trabalho em nome dos proprietários. Estes são os administradores.

Ora, olhando para frente, desde a emergência da Escola das Relações Humanas, que alterou o foco das pesquisas das técnicas de trabalho como forma de controle do trabalhador para o controle do trabalhador por meio da gestão das relações sociais do trabalhador e até de seus padrões de significação do trabalho ${ }^{9}$, não há nenhuma corrente teórica ou de pesquisa que investigue de forma explícita exatamente aquilo que o taylorismo investigava. Isso não significa que os princípios e a mentalidade taylorista não permaneçam bem vivos na cultura do management ${ }^{10}$, interiorizados tanto em outras linhas de pesquisa, notadamente na área de operações, quanto em práticas tidas como de excelência, tais como as certificações de qualidade do tipo ISO.

Desde então, as pesquisas centradas no trabalhador e suas relações com e na organização, tornaram-se gradativamente objeto daquilo que se constituiu na disciplina de Comportamento Organizacional, como veremos adiante. Isso ocorreu, sobretudo a partir da década de 1970, num contexto de crescente "toyotização" do trabalho, materializado em práticas administrativas como grupos multidisciplinares autogeridos e produção flexível e/ou personalizada. Essas técnicas significavam um retorno de fato a modelos pré-tayloristas de organização do trabalho ${ }^{11}$, mas, sobretudo, importavam em mecanismos de captura da subjetividade do trabalhador. Tal captura ocorre pela

7 Sobre isso, Cf. Alvesson e Deetz (1999), Melo (2019) e Paço-Cunha e Ferraz (2018).

8 Sobre isso, Cf. Boal, Hunt e Jaros (2003), Böhm (2006), Chia (2003), Paço-Cunha (2010) e Westwood e Clegg (2003).

9 Sobre este último ponto, Cf. Lips-Wiersma e Morris (2009).

10 Cultura do management é uma noção vigente que limita a leitura das diversas dimensões da experiência social ao uso das categorias do mundo dos negócios (Wood Jr. \& Paula, 2006).

11 Caracterizar esse retorno requer adentrar questões que extrapolam o escopo deste ensaio. Nossa posição se sustenta na discussão acerca da subsunção formal e real nos termos colocados por Ruy Fausto (1989). 
representação das expectativas dos trabalhadores em valores-fetiche, pela sua representação como parceiros ou colaboradores (internalizando assim os imperativos da produtividade) e, principalmente, pela "apropriação não apenas de habilidades técnico-profissionais da força de trabalho, mas também de disposições subjetivas/anímico-volitivas do trabalho vivo em prol dos interesses da produção de mercadorias" (Alves, 2014, p. 59).

Por outro lado, olhando para trás, a preocupação com a tarefa não surgiu com Taylor, tendo sido discutida extensamente sob a forma de divisão do trabalho. Basta pensar, por exemplo, nas ideias de Adam Smith, Karl Marx, Charles Babbage e Andrew Ure (para não adentrar outra esfera, de textos ainda mais antigos como A República de Platão, Trabalhos e dias de Hesíodo ou mesmo a Torá judaica). Isso significa, portanto, que o taylorismo não foi o início, mas o ápice da elaboração teórica sobre a divisão do trabalho.

Logo, considerar que a investigação do trabalho delimita o início da administração como campo de pesquisa é uma hipótese que apresenta problemas. O que parece "novo" em Taylor é que a atenção ao trabalho aparece como um fim em si mesmo. Ele suprimiu a discussão sobre os interesses que movem a busca pelo aumento da eficiência, encapsulando-a numa espécie de valor moral. Para confirmar isso, basta verificar as palavras com as quais ele compõe sua abertura: uma espécie de sermão contra o desperdício e uma apologia da eficiência. Restou oculta sua subordinação ao imperativo da criação de outro tipo de valor: o lucro.

Assim, parece-nos possível e razoável considerar o início da administração não a partir da busca por entender e gerenciar diretamente $o$ trabalho e suas implicações sociais, mas precisamente no movimento que ocultou as implicações envolvidas na busca por eficiência e substituiu uma discussão aberta sobre esse tema pela busca por entender e gerenciar o trabalhador.

\section{Weber, Fayol e a administração como ciência da organização}

A organização foi um tema importante para Weber e, igualmente importante, foi a contribuição dele para o pensamento administrativo. Metodologicamente, Weber operava a partir da criação de tipos ideais, e isso pode explicar a existência de definições tão abstratas e reificadas de organização como as que temos até hoje (outra possível explicação é a ocultação dos interesses representados nas organizações como forma de reduzir as tensões sociais e atenuar a percepção dos conflitos interiorizados nesta).

O grande tema da sociologia weberiana foi a racionalização e, no campo organizacional, ele identificou que as burocracias (que viriam a ficar conhecidas como organizações racionais) apresentavam melhor desempenho quando submetidas aos critérios muito específicos da racionalidade prática, aquela que se consolidava como mais importante nas circunstâncias históricas investigadas por ele.

Weber foi introduzido no cenário norte-americano a partir de uma tradução problemática de Economia e sociedade feita na década de 1930 pelo sociólogo Talcott Parsons. O problema com essa tradução é que Parsons apresenta o conceito de burocracia como um tipo não somente ideal por ser produto de uma abstração, mas ideal no sentido de ser desejável pela sua eficiência (Mardsen \& Townley, 1996). Nada mais distante do pensamento de Weber, que estava preocupado com a racionalização e particularmente com os administradores, esses "especialistas sem alma". Na década de 1960, os estudos de Aston, que buscaram relacionar diferentes conjuntos de variáveis e seus efeitos a diferentes dimensões e categorias de organizações burocráticas, consolidaram definitivamente a prescrição burocrática na lente funcionalista da administração (Perrow, 1991) e, juntamente com ela, a noção reificada de organização.

Por outro lado, o livro de Fayol (1916/1989), na medida em que representava o testemunho de um administrador de fato (engenheiro de formação, assim como Taylor), deu aos proprietários e 
administradores um sentido prático e imediatamente aplicável do termo organização como um ente próprio, uma coisa em si. Ao descrever os departamentos e funções de uma empresa e apresentar conselhos para os futuros engenheiros sobre como se conduzir profissionalmente na função de administradores, Fayol compôs um verdadeiro manual de instruções simples e funcional. Seu alcance só não foi maior pois permaneceu relativamente desconhecido do público americano até a década de 1960.

É evidente que essas apropriações imprecisas dos conceitos weberianos e prescrições empíricas de Fayol não criaram as organizações modernas, mas contribuíram de forma relevante para legitimálas teórica e ideologicamente, assim como as racionalidades que elas representam. Dessa maneira, a noção de organização, tomada como um ente próprio, pôde avançar pela sociedade hegemonizando suas lógicas instrumentais características. No limite, passamos a enxergar e chamar de sociedade, na sua maior parte, o conjunto dessas organizações com as quais interagimos, como igrejas, prefeituras, empresas, clubes, condomínios e até associações comunitárias (Perrow, 1991).

É precisamente no espaço formado entre esses dois momentos da administração, isto é, entre o estudo do trabalhador e o das organizações, que surgem e se posicionam, para dar conta das técnicas necessárias ao controle da força de trabalho, a disciplina das relações industriais (que posteriormente passou a ser chamada de administração de recursos humanos e, mais recentemente, de gestão de pessoas) e, para teorizar a respeito do comportamento humano no trabalho e das relações sociais que se desenvolvem nesse ambiente, a disciplina de Comportamento Organizacional, que é o que mais nos interessa aqui.

\section{Comportamento Organizacional: síntese das ciências do trabalhador e da organização}

Desde o final do século XIX, os psicólogos começaram a estudar formas de selecionar candidatos mais adequados às suas futuras tarefas. Foram esses estudos que abriram as portas do mundo do trabalho para a psicologia. Essa atuação ficou inicialmente restrita ao nível individual e aos processos de recrutamento, seleção e alocação de trabalhadores nas grandes corporações e soldados no exército. Os apelos de Elton Mayo para a inclusão de outros aspectos sociais e subjetivos nos estudos em administração, que datam de 1939, precisaram esperar até o final da década de 1950 para serem atendidos.

Mas, em 1959, dois relatórios patrocinados por empresas privadas avaliaram as escolas de negócios dos Estados Unidos e demandaram grandes mudanças em seus currículos, pesquisas e professores. Esses relatórios, encomendados pela Carnegie Corporation e pela Ford, criticavam as escolas de negócios e recomendavam que concentrassem seus estudos na área comportamental e criassem agendas de pesquisa de maior relevância (Porter \& Schneider, 2014). As escolas de negócios, então, criaram novos departamentos, com maiores verbas para pesquisa e melhores salários para os professores, atraindo para as novas vagas principalmente pesquisadores das áreas de sociologia e psicologia social. Foram os estudos e publicações realizados por esses departamentos, que investigavam variáveis subjetivas e sociais no âmbito do trabalho, que consolidaram a disciplina que ficou conhecida como Comportamento Organizacional (Mitchell, 2018; Porter \& Schneider, 2014; Staw, 2016).

Inicialmente ocupados com questões relacionadas à produtividade e ao absenteísmo, os pesquisadores dessa nascente disciplina sentiram-se pressionados para adaptarem seus estudos para atender o que foi chamado de "necessidades do mundo organizacional" ou, como normalmente se fala, produzir pesquisa relevante. Evidentemente, relevância é uma determinação concretamente localizada e, no cenário onde a ideia reificada de organização avança, a ponto de se falar em uma 
"sociedade de organizações", considera-se relevante aquilo que é importante "para a organização". Mas essa forma de se referir às organizações, como portadoras de interesses, é também uma maneira de reificá-la, pois esconde os personagens que, agindo e interagindo, formam isso mesmo a que se denomina organização. Em outras palavras, essa reificação faz com que uma estrutura social, que corresponde ao conjunto das ações das pessoas e suas relações (Weber, 1922/1978), seja naturalizada como uma entidade dada e autoevidente (Alvesson \& Deetz, 1999). A organização deve ser tratada como uma abstração dos indivíduos e das relações sociais que se desenvolvem na vida moderna (Mardsen \& Townley, 1996), uma ficção, um adensamento nas relações entre as pessoas (Davis \& Marquis, 2005).

É a abertura para a possibilidade de entender as organizações dessa maneira, como uma expressão das relações sociais entre diferentes sujeitos, que evita que os estudos em Comportamento Organizacional caiam completamente na armadilha do fetichismo da organização como coisa em si, tantas vezes presente em outros campos dos estudos organizacionais. Nesse sentido, nosso argumento é que Comportamento Organizacional está mais bem posicionado para explicar os processos organizativos, o que justifica nossa primeira proposição:

Proposição 1: No campo de investigações sobre os processos organizativos, os estudos em Comportamento Organizacional estão mais bem posicionados para compreender os fenômenos sociais que compõem as relações de trabalho.

Por outro lado, esse bom posicionamento não está isento de problemas. O conhecimento produzido pelo Comportamento Organizacional é muitas vezes instrumentalizado a partir de uma perspectiva utilitarista e manipulatória. Além disso, o debate sobre quão organizacional deveria ser a pesquisa sobre Comportamento Organizacional pode indicar um avanço da perspectiva reificada de organização sobre os domínios dessa disciplina. Avançaremos sobre esses dois pontos nas próximas seções.

\section{Crítica à dimensão valorativa (utilitária) do Comportamento Organizacional}

A crítica à dimensão valorativa tem a ver com o utilitarismo associado às pesquisas em Comportamento Organizacional, algo reconhecido, inclusive, por pesquisadores importantes da área. Mitchell (2018) afirma que, durante muito tempo, os estudos em Comportamento Organizacional permaneceram focados em temas que pudessem ser diretamente associados ao aumento da produtividade ou à lealdade dos trabalhadores para com a organização. Staw (2016, p. 12.12) conta que, até o fim dos anos 1970, corria uma piada entre os pesquisadores desse campo sobre certa monotonia em seus estudos, que sempre tinham como variáveis dependentes o desempenho, o absenteísmo, a rotatividade ou a satisfação com o trabalho.

O utilitarismo dos estudos em Comportamento Organizacional também fica evidente no uso da díade necessidade-satisfação como o tipo de articulação fundamental, sem que isso dê conta de explicar adequadamente as relações de trabalho (Nord \& Fox, 1999). Isso aparece, por exemplo, nas próprias definições dos constructos investigados. Considere, por um momento, as definições de comprometimento com o trabalho (que talvez, para manter-se a coerência com a noção reificada de organização, devesse ser rebatizada como comprometimento com a organização) e de cidadania organizacional e verá que elas focalizam explicitamente um objetivo utilitarista: conseguir que os trabalhadores façam mais do que o esperado/acordado sem necessariamente receber ou requerer nenhuma recompensa (sobretudo econômica) (Mitchell, 2018; Robins, Judge \& Sobral, 2010; Solinger, Olffen \& Roe, 2008). Mas nós gostaríamos de nos deter em um aspecto mais sutil dessa dimensão valorativa. 
Nossa crítica está relacionada ao questionamento sobre de quem são os interesses contemplados pela pesquisa em Comportamento Organizacional. No livro Princípios de administração científica, Taylor (1911/1990) retrata claramente a existência de "lados" no ambiente organizacional. Ele, que havia sido um supervisor de primeira linha, ombreando com os trabalhadores mais simples, quando se viu alçado a uma posição gerencial não tardou em esclarecer aos seus ex-companheiros que agora estava "servindo à direção", o que iniciou uma "guerra atroz" (Taylor, 1911/1990, p. 48). Essa passagem ilustra e esclarece os termos sobre os quais se forma o pensamento administrativo. Não se trata de buscar um conhecimento técnico supostamente neutro para a mediação dos interesses de diferentes grupos sociais. Trata-se, pelo contrário, de um campo de conhecimento abertamente servil aos interesses de um grupo social determinado: os proprietários das empresas ${ }^{12}$.

Brief (2000) apresenta três faces da submissão dos pesquisadores em Comportamento Organizacional a interesses específicos. Primeiro, ele fala da escolha exclusiva ou majoritária de variáveis independentes que podem ser gerenciadas pelos administradores, e a consequente desconsideração de outras variáveis com igual ou maior poder de explicação. Segundo, ele comenta que os esforços dos acadêmicos para se aproximar do "mundo real" são sempre na direção de se aproximar dos gerentes (embora isso ainda pareça uma imprecisão, pois aquilo que aparece como objetivo dos gerentes é, na maioria das vezes, objetivo do proprietário) e não de atender as necessidades dos consumidores ou de entender como melhorar a qualidade de vida no trabalho. Por fim, em terceiro lugar, ele apresenta um argumento ainda mais radical, propondo que, se a pesquisa toma partido da gerência, ainda que implicitamente, e, se há conflito de interesse entre o que a gerência quer e o bem maior da sociedade, a pesquisa em Comportamento Organizacional apresenta problemas éticos. Becker (1967, p. 241) destaca que, curiosamente, os pesquisadores são acusados de parcialidade apenas quando problematizam questões e realizam estudos favoráveis aos grupos ditos "subordinados" da sociedade, o que evidenciaria o que ele chamou de "hierarquia da credibilidade".

Esse debate também se reflete (e se mascara) na discussão sobre a função dos administradores. Oficialmente são eles que determinam os objetivos comuns da organização e definem as tarefas a serem realizadas. Aparecem, portanto, como um intermediário neutro e técnico entre os interesses dos proprietários e dos trabalhadores. Mas esse é um discurso autocentrado, apologético e legitimador. A autonomia para a determinação de objetivos é apenas superficial e aparente. Há sempre um objetivo maior que permanece intocado: a maximização dos resultados financeiros para os proprietários.

Alguém sempre poderá argumentar que o conceito de organização é mais abrangente que o conceito de empresa, e que aquela, diferentemente desta, não necessita ter objetivos econômicos (fins lucrativos). Nossa posição é que essa afirmação, apesar de conceitualmente exata, não se presta inteiramente a uma contraposição ao nosso argumento. Isso porque, de um lado, existe uma tendência de a esfera econômica "colonizar" todas as outras esferas da vida, um tema já debatido até mesmo especificamente no campo da teoria organizacional (e.g. Ramos, 1981). Por outro lado, a própria ideia de objetivos da organização pode ser considerada uma espécie de fetichismo, posto que, no mundo real, somente pessoas podem realmente formular objetivos. O que se denomina de objetivo organizacional nada mais é do que um disfarce para legitimar os interesses de alguém, objetivos que pessoas reais podem, no máximo, compartilhar. Assim, nossa primeira crítica pode ser sintetizada na seguinte proposição:

Proposição 2: Os temas e direcionamentos das pesquisas em Comportamento Organizacional refletem, sob expressões reificadas como "objetivos da organização", uma valoração dos interesses dos proprietários, ainda que esses interesses permaneçam implícitos.

12 Sobre essa questão, Cf. também Braverman (1974/1998). 
Essa constatação, mais evidente, sobre a valoração implícita nos estudos em Comportamento Organizacional, dá origem a outra, menos evidente, sobre a consideração da organização como coisa em si. Essa última questão é o ponto de partida da segunda crítica que apresentaremos a seguir.

\section{Crítica à dimensão conceitual do Comportamento Organizacional}

Na crítica à dimensão conceitual do Comportamento Organizacional, nosso foco é o conceito reificado de organização e o seu avanço sobre as questões relacionais que compõem a realidade social. Por reificação, nos referimos ao ato de tomar um conjunto de relações sociais por uma coisa em si, uma entidade real e concreta ${ }^{13}$. Por exemplo, na sua importante reflexão sobre a evolução do campo de Comportamento Organizacional, Staw (2016, p. 12.12, tradução nossa) afirma que "um evento pode inicialmente atingir a organização e seus impactos então serem filtrados até o membro individual". Ora, o que poderia "atingir" uma organização? Evidentemente trata-se de uma alegoria (atingir) sobre uma abstração (organização). E aqui, o problema não é a impossibilidade de se expressar dessa maneira, mas de não se considerar essa expressão efetivamente uma alegoria e uma abstração. O problema é acreditar que a organização existe no plano concreto independentemente das pessoas e das relações sociais que a constituem.

Mas a reificação não possui apenas consequências no campo das ideias. A constituição de uma pessoa jurídica, com direitos equivalentes aos de uma pessoa física - um exercício de reificação -, coloca em clara desvantagem o trabalhador que com ela se relaciona oferecendo "sua própria pele". Uma pessoa jurídica não pode ser penalizada tão profundamente quanto uma pessoa física, pois não tem corpo que possa ser lançado em uma cela. Não tem psique, moral ou valor próprio que possam ser abalados ou sequer honra ou reputação para serem manchadas. Aos que duvidam desse último ponto alegando a importância da gestão da marca e da reputação, lembramos que em muitos escândalos corporativos são os administradores que são identificados como bodes expiatórios, como apenas "algumas maçãs podres" (Bakan, 2008). Outro expediente disponível apenas para as pessoas jurídicas é a simples mudança de nome, com o qual se apaga do imaginário do público toda uma história passada.

A reificação, portanto, se expressa tanto no nível das representações e mediações teóricas quanto no nível da experiência concreta. Ela permite o "posicionamento" da organização de maneira que possa ser teoricamente manipulada e concretamente administrada, bem ao gosto positivista (Böhm, 2006). Na organização reificada, a impessoalidade de Weber funciona não só como uma ausência de privilégios, mas também como uma ausência de humanidade. Ninguém comanda, ninguém decide (e, consequentemente, ninguém é efetivamente responsável). São "leis" e "forças" que governam e determinam prioridades, normas e métodos, criando uma espécie de controle pan-óptico ${ }^{14}$ muito efetivo e pouco sujeito a resistências. A integração dos trabalhadores também é facilitada pela substituição de complexas interações e negociações por regulamentos supostamente racionais, impessoais e neutros que criam uma cooperação mecânica e uma sensação de destino comum (Perrow, 1991).

No plano da linguagem, a reificação (des)aparece através de metonímias ou substituições na fala corrente que ocultam agentes e seus interesses concretos. Fala-se em "objetivos da organização" quando se trata, na verdade, de interesses dos proprietários e dos administradores

13 Cf. Marx (1867/2013), Mészáros (2016) e Netto (1981).

14 Na ilustração muito conhecida após sua utilização por Foucault (1987), o pan-óptico era um mecanismo utilizado em uma prisão na qual os presos nunca sabiam se estavam ou não sendo observados e, portanto, viam-se obrigados a agir como se permanentemente o estivessem. Esse é o mesmo efeito da despersonalização do controle nos arranjos organizacionais. A figura e a presença física de um chefe não são mais necessárias, a ordem está internalizada em cada indivíduo. 
(Alvesson \& Deetz, 1996; Mardsen \& Townley, 1996), ou em “mercado insatisfeito”, quando se trata apenas de investidores contrariados. As noções de desenvolvimento e progresso, nesse contexto, são identificadas imediatamente com o desenvolvimento da eficiência e da produtividade. A organização, agora reificada, passa a ser o modelo de arranjo produtivo de referência a ser adotado (Perrow, 1991), e os teóricos organizacionais são vistos como em melhor posição para compreender a sociedade (Davis \& Marquis, 2005). Na medida em que até a compreensão dos diversos fenômenos é mediada por essa noção de organização, diminui a possibilidade de conceber um mundo diferente de uma "sociedade organizacional". Por fim, a reificação termina por identificar sujeito e objeto, naturalizando e imobilizando as percepções sobre as dinâmicas sociais e da história (Bronner, 1994). Enquanto a organização passa de objeto de estudo a sujeito (Davis \& Marquis, 2005), as pessoas passam a serem tratadas como objetos numa burocracia irresponsável. É assim que as pessoas e a ação humana desaparecem sob o conceito reificado de organização.

A mediação das organizações e a assimilação das suas racionalidades pelos trabalhadores resultam em uma visão específica sobre o sujeito que trabalha. Na medida em que a sociedade é representada pelo conjunto de organizações, as atividades econômicas e produtivas precisam necessariamente passar por estas. A categoria trabalho e a relação indivíduo-trabalho, então, perdem sua força explicativa, pois não se concebem relações sociais fora das organizações. Isso faz com que a identidade sujeito-objeto apareça como identidade trabalhador-organização, que a relação indivíduo-trabalho se reduza à relação de emprego e, finalmente, que a vida se reduza à experiência profissional, incluindo-se aí a omnipresente dimensão do consumo ${ }^{15}$. Nesse contexto, a classe trabalhadora poderia se chamar simplesmente de classe empregada (Perrow, 1991). Assim, as gramáticas da organização e da administração (Reed, 1996) alienam os trabalhadores na prática e invisibilizam o trabalho e os trabalhadores na sua produção teórica. Em síntese, esta segunda crítica pode ser formulada assim:

Proposição 3: A tendência do aumento da dimensão organizacional na disciplina de Comportamento Organizacional é uma tendência reificante que implica a redução daquele componente que lhe permite explicar adequadamente os fenômenos sociais no âmbito dos processos organizativos, qual seja: a consideração do trabalhador como sujeito.

\section{Considerações finais}

As relações entre as pessoas estão no centro de qualquer produção social. Isso coloca a disciplina de Comportamento Organizacional em posição de vantagem na compreensão dos fenômenos sociais relacionados aos processos organizativos, sem, no entanto, livrá-la de armadilhas como as que tentamos apresentar neste ensaio.

Ainda assim, não são poucos os teóricos que defendem um aumento do componente organizacional sobre o componente comportamental ou subjetivo na disciplina ${ }^{16}$. Embora a intenção desses autores seja apontar caminhos para aumentar a aderência das pesquisas à realidade e, consequentemente, sua relevância social e o poder explicativo da teoria resultante, esse pode ser um movimento estéril ou mesmo contraproducente, caso não se observem os perigos da instrumentalização das pesquisas e da reificação dos conceitos.

Outro aspecto que merece atenção - e sobre o qual há um extenso debate de natureza crítica - é a mudança da dinâmica das relações sociais de produção que se referem a temas próprios

15 Cf. Tausky (1969).

16 Entre eles, Heath e Sitkin (2001), Porter e Schneider (2014) e Staw (2016). 
da disciplina de Comportamento Organizacional ${ }^{17}$. Entre alguns pesquisadores importantes da área (e.g. Brief, 2000; Mitchell, 2018), destaca-se a percepção de que a pesquisa mudou seu foco instrumental para o entendimento da qualidade da experiência com o trabalho. Isso significaria que, atualmente, a preocupação com a produtividade se estende às práticas de respeito no tratamento dos empregados. Haveria agora uma visão mais equilibrada sobre o que acontece realmente nas relações de trabalho. Nossa posição a esse respeito é francamente cética. Nossa hipótese é que a "evolução" nos temas tratados pelos estudos em Comportamento Organizacional - por exemplo, da simples procura de preditores para o absenteísmo à investigação das causas de bem-estar dos funcionários - são apenas os reflexos da reformulação no formato do conflito gerência-trabalho (o que nos parece um eufemismo para o conflito capital-trabalho), na medida em que esse conflito assume formas mais sutis como grupos autogeridos e outros mecanismos de flexibilização toyotista.

Nesse ponto, reproduzimos as palavras de Staw (2016, p. 12.14, tradução nossa), que afirma que "nosso campo [Comportamento Organizacional] toma o bem-estar corporativo como o fim a ser atingido em vez da perspectiva da comunidade mais ampla ... poucos de nós [pesquisadores] tiveram a coragem de adotar uma perspectiva extremamente centrada no empregado".

Todas as questões levantadas neste ensaio parecem indicar a necessidade de uma teoria mais substantiva sobre os processos organizativos. Uma teoria que dê conta da contínua produção simbólica do ser humano (Jung, 2008), da sua "vontade de sentido" (Frankl, 2006), da centralidade fundamental do trabalho (Arendt, 2016; Lukács, 1980; Marx, 1845/2007, 1867/2013) ${ }^{18}$, e das formas de organização elaboradas a partir da produção de sentidos, significados e da vontade humana. Particularmente, acreditamos que essa teoria será fruto, dentre outras possibilidades, de uma pesquisa centrada sobre a investigação dos sentidos e significados do trabalho.

\section{Referências}

Abílio, L. C. (2014). Sem maquiagem: o trabalho de um milhão de revendedoras de cosméticos. São Paulo: Boitempo.

Alves, G. (2014). A disputa pelo intangível: estratégias gerenciais do capital na era da globalização. In R. Antunes (Org.), Riqueza e miséria do trabalho no Brasil III (pp. 55-72). São Paulo: Boitempo.

Alvesson, M. \& Deetz, S. (1999). Critical theory and postmodernism: approaches to organizational studies. In S. R.

Clegg, \& C. Hardy (Eds.), Studying organizations: theory and method (pp. 185-211). London: Sage.

Antunes, R. (2002). Adeus ao trabalho? Ensaio sobre as metamorfoses e a centralidade do mundo do trabalho. São Paulo: Cortez.

Arendt, H. (2016). A condição humana. Rio de Janeiro: Forense Universitária.

Bakan, J. (2008). A corporação: a busca patológica por lucro e poder. São Paulo: Novo Conceito.

Becker, H. S. (1967). Whose side are we on? Social Problems, 14 (3), 239-247.

Boal, K. B., Hunt, J. G. \& Jaros, S. J. (2003). Order is free: on the ontological status of organizations. In R. Westwood \& S. Clegg (Eds.), Debating organization: point-counterpoint in organization studies (pp. 84-98). Oxford: Blackwell.

Böhm, S. (2006). Positioning organization theory. In S. Böhm, Repositioning organization theory: Impossibilities and strategies (pp. 3-25). New York: Palgrave Macmillan.

Braverman, H. (1998). Labor and monopoly capital: the degradation of work in the twentieth century. New York: Monthly Review Press. (Trabalho original publicado em 1974)

Brief, A. (2000). Still servants of power. Journal of Management Inquiry, 9 (4), 342-351.

Bronner, S. E. (1994). Philosophical anticipations: a commentary on the "reification" essay of Georg Lukács. In S. E. Bronner, Of critical theory and its theorists (pp. 32-61). Cambridge: Blackwell.

17 Sobre o tema, Cf. Abílio (2014), Antunes (2002), Gorz (1989) e Lazzarato e Negri (2013).

18 Cf. também Duayer (2015) e Fortes (2016) para uma crítica às visões simplistas ou redutoras acerca da centralidade do trabalho.

\section{6}


Chia, R. (2003). Ontology: organization as “world-making”. In R. Westwood \& S. Clegg (Eds.), Debating organization: point-counterpoint in organization studies (pp. 98-113). Oxford: Blackwell.

Clegg, S. R., \& Hardy, C. (1996). Introduction: organizations, organization and organizing. In S. R. Clegg, C. Hardy \& W. R. Nord (Eds.), Handbook of organizational studies (pp. 1-28). London: Sage.

Davis, G. F. \& Marquis, C. (2005). Prospects for organizational theory in the early twenty-first century: institutional fields and mechanisms. Organization Science, 16 (4), 332-343.

Drucker. P. F. (1993). The concept of the corporation. London: Routledge.

Duayer, M. (2015). Crítica ontológica em Marx. In J. P. Netto (Org.), Curso livre Marx-Engels: a criação destruidora (pp. 115-137). São Paulo: Boitempo.

Fausto, R. (1989). A “pós-grande indústria” nos Grundrisse (e para além deles). Lua Nova, 19, 47-68.

Fayol, H. (1989). Administração industrial e geral: previsão, organização, comando, coordenação e controle. São Paulo: Atlas. (Trabalho original publicado em 1916)

Fortes, R. V. (2016). As três determinações fundamentais da análise lukacsiana do trabalho: modelo das formas superiores, prioridade ontológica e abstração isoladora. Crítica da ideia da centralidade do trabalho em Lukács. Verinotio, 11 (22), 44-75.

Foucault, M. (1987). Vigiar e punir: nascimento da prisão (20aㅡed.). Petrópolis, RJ: Vozes.

Frankl, V. (2006). Men's search for meaning. Boston: Beacon Press.

Gorz, A. (1989). Critique of economic reason. London: Verso.

Heath, C. \& Sitkin, S. B. (2001). Big-B versus Big-O: what is organizational about organizational behavior? Journal of Organizational Behavior, 22 (1), 43-58.

Jung, C. G. (2008). Chegando ao inconsciente. In C. G. Jung (Org.), O homem e seus símbolos (pp. 15-131). Rio de Janeiro: Nova Fronteira.

Kuhn, T. (2017). A estrutura das revoluções científicas (13aㅡ ed.). São Paulo: Perspectiva.

Lazzarato, M. \& Negri, A. (2013). Trabalho imaterial: formas de vida e produção da subjetividade. Rio de Janeiro: Lamparina.

Lips-Wiersma, M. \& Morris, L. (2009). Discriminating between 'meaningful work' and the 'management of meaning'. Journal of Business Ethics, 88 (3), 491-511.

Lukács, G. (1980). Labour (the ontology of social being). London: Merlin Press.

Mardsen, R. \& Townley, B. (1996). The owl of minerva: reflections of theory in practice. In S. R. Clegg, C. Hardy \& W. R. Nord (Eds.), Handbook of organizational studies (pp. 659-675). London: Sage.

Marx, K. (2007) A ideologia alemã. São Paulo: Boitempo. (Trabalho original publicado em 1845)

Marx, K. (2013). O capital: crítica da economia política - livro 1. São Paulo: Boitempo. (Trabalho original publicado em 1867)

Melo, N. (2019). Significados do trabalho na literatura popular de gestão. Dissertação de Mestrado, Centro de Ciências Sociais Aplicadas, Universidade Federal de Pernambuco, Recife.

Mészáros, I. (2016). A teoria da alienação em Marx. São Paulo: Boitempo.

Mitchell, T. R. (2018). A dynamic, inclusive, and affective evolutionary view of organizational behavior. Annual Review of Organizational Psychology and Organizational Behavior, 5, 1-19.

Netto, J. P. (1981). Capitalismo e reificação. São Paulo: Ciências Humanas.

Nord, W. R. \& Fox, S. (1999). The individual in organizational studies: the great disappearing act? In S. R. Clegg \& C. Hardy (Eds.), Studying organizations: theory and method (pp. 142-168). London: Sage.

Paço-Cunha, E. (2010). Marx e a organização como abstração arbitrária. 6o Encontro de Estudos Organizacionais da ANPAD (pp. 1-7). Florianópolis: ANPAD. Recuperado de https://bit.ly/2YuOjIS

Paço-Cunha, E. \& Ferraz, D. L. (Orgs.). (2018). Crítica marxista da administração. Rio de Janeiro: Rizoma.

Perrow, C. (1991). A society of organizations. Theory and Society, 20 (6), 725-762.

Porter, L. W. \& Schneider, B. (2014). What was, what is, and what may be in OP/OB. Annual Review of Organizational Psychology and Organizational Behavior, 1, 1-21.

Ramos, A. G. (1981). The new science of organizations: reconceptualization of the wealth of nations. Toronto, ON: University of Toronto Press. 
Reed, M. (1996). Organizational theorizing: a historically contested terrain. In S. R. Clegg, C. Hardy \& W. R. Nord (Eds.), Handbook of organizational studies (pp. 31-56). London: Sage.

Robbins, S. P., Judge, T. A. \& Sobral, F. (2010). O que é comportamento organizacional? In S. Robbins, T. Judge \& F. Sobral, Comportamento organizacional: teoria e prática no contexto brasileiro (pp. 1-36). São Paulo: Pearson Prentice Hall.

Solinger, O. N., Olffen, W. \& Roe, R. A. (2008). Beyond the three-component model of organizational commitment. Journal of Applied Psychology, 93 (1), 70-83.

Spink, P. K. (1996). A organização como fenômeno psicossocial: notas para uma redefinição da psicologia do trabalho. Psicologia E⿱乛 Sociedade, 8 (1), 174-192.

Staw, B. M. (2016). Stumbling toward a social psychology of organizations: an autobiographical look at the direction of organizational research. Annual Review of Organizational Psychology and Organizational Behavior, 3, 12.1-12.19.

Tausky, C. (1969). Meanings of work among blue-collar men. The Pacific Sociological Review, 12 (1), 49-55.

Taylor, F. W. (1990). Princípios de administração científica. São Paulo: Atlas. (Trabalho original publicado em 1911)

Weber, M. (1978). Economy and society: an outline of interpretative sociology. Berkeley: University of California Press. (Trabalho original publicado em 1922)

Weick, K. (1979). The social psychology of organizing (2a ed.). Reading, MA: Addison-Wesley Publishing Company.

Westwood, R. \& Clegg, S. (2003). Commentary: let's get ontological. In R. Westwood \& S. Clegg (Eds.), Debating organization: point-counterpoint in organization studies (pp. 83-84). Oxford: Blackwell.

Wood Jr., T. \& Paula, A. P. P. (2006). A mídia especializada e a cultura do management. Organização Ė Sociedade, $13(38), 91-105$.

\section{Endereço para correspondência} newtonclaizoni@gmail.com
Recebido em: 03/01/2019

Revisado em: 25/06/2019

Aprovado em: 05/07/2019 